\title{
Serum L-arginine and Dimethylarginine Levels in Migraine Patients with Brain White Matter Lesions
}

\begin{tabular}{|c|c|}
\hline Journal: & Cephalalgia \\
\hline Manuscript ID & CHA-00272-OA-2015.R2 \\
\hline Manuscript Type: & Original Article \\
\hline Date Submitted by the Author: & $\mathrm{n} / \mathrm{a}$ \\
\hline Complete List of Authors: & $\begin{array}{l}\text { Erdélyi-Bótor, Szilvia; University of Pécs, Faculty of Medicine, Department } \\
\text { of Neurology } \\
\text { Komáromy, Hedvig; Diagnostic Center of Pécs, Diagnostic Center } \\
\text { Olayinka, David; University of Pécs, Faculty of Medicine, Department of } \\
\text { Neurology } \\
\text { Kovács, Norbert; University of Pécs, Department of Neurology } \\
\text { Perlaki, Gábor; University of Pécs, Faculty of Medicine, Department of } \\
\text { Neurology; Diagnostic Center of Pécs, Diagnostic Center ; MTA-PTE Clinical } \\
\text { Neuroscience MR Research Group, MTA-PTE Clinical Neuroscience MR } \\
\text { Research Group } \\
\text { Orsi, Gergely; University of Pécs, Faculty of Medicine, Department of } \\
\text { Neurology; Diagnostic Center of Pécs, Diagnostic Center; MTA-PTE Clinical } \\
\text { Neuroscience MR Research Group, MTA-PTE Clinical Neuroscience MR } \\
\text { Research Group } \\
\text { Molnár, Tihamér; University of Pécs, Faculty of Medicine, Department of } \\
\text { Anesthesiology and Intensive Care } \\
\text { Illes, Zsolt; University of Pécs, Faculty of Medicine, Department of } \\
\text { Neurology } \\
\text { Nagy, Lajos; University of Debrecen, Department of Applied Chemistry } \\
\text { Kéki, Sándor; University of Debrecen, Department of Applied Chemistry } \\
\text { Deli, Gabriella; University of Pécs, Faculty of Medicine, Department of } \\
\text { Neurology } \\
\text { Bosnyák, Edit; University of Pécs, Faculty of Medicine, Department of } \\
\text { Neurology } \\
\text { Trauninger, Anita; University of Pécs, Faculty of Medicine, Department of } \\
\text { Neurology } \\
\text { Pfund, Zoltan; University of Pécs, Faculty of Medicine, Department of } \\
\text { Neurology }\end{array}$ \\
\hline Key Words: & $\begin{array}{l}\text { migraine, white matter lesion, symmetric and asymmetric } \\
\text { dimethylarginine, L-arginine, oxidative stress, endothelial dysfunction }\end{array}$ \\
\hline
\end{tabular}

\section{SCHOLARONE ${ }^{m}$ \\ Manuscripts}




\title{
Serum L-arginine and Dimethylarginine Levels in Migraine Patients with
} Brain White Matter Lesions

\author{
Szilvia Erdélyi-Bótor, $\mathrm{MD}^{1}$, Hedvig Komáromy, $\mathrm{MD}^{2}$, David Olayinka Kamson, $\mathrm{MD}, \mathrm{PhD}^{1}$, \\ Norbert Kovács, MD, $\mathrm{PhD}^{1}$, Gábor Perlaki, $\mathrm{PhD}^{1,2,3}$, Gergely Orsi, $\mathrm{PhD}^{1,2,3}$, \\ Tihamér Molnár, MD, $\mathrm{PhD}^{4}$, Zsolt Illes, MD, PhD, $\mathrm{DSc}^{1}$, Lajos Nagy, $\mathrm{PhD}^{5}$, Sándor Kéki, \\ $\mathrm{PhD}, \mathrm{DSc}^{5}$, Gabriella Deli, $\mathrm{MD}^{1}$, Edit Bosnyák, $\mathrm{MD}^{1}$, Anita Trauninger, $\mathrm{MD}, \mathrm{PhD}^{1}$, \\ Zoltán Pfund, $\mathrm{MD}, \mathrm{PhD}^{1}$ \\ Department of Neurology, University of Pécs ${ }^{1}$, Pécs, Hungary \\ Diagnostic Center of Pécs ${ }^{2}$, Pécs, Hungary \\ MTA-PTE Clinical Neuroscience MR Research Group ${ }^{3}$, Pécs, Hungary \\ Department of Anesthesiology and Intensive Care, University of Pécs ${ }^{4}$, Pécs, Hungary \\ Department of Applied Chemistry, University of Debrecen ${ }^{5}$, Debrecen, Hungary
}

\begin{abstract}
Address correspondence:
Zoltán Pfund, MD, PhD

Department of Neurology, Faculty of Medicine, University of Pécs

7623 Pécs, Rét u. 2. Hungary

Email: pfund.zoltan@pte.hu, phone: +3672535900
\end{abstract}

\begin{abstract}
Background/Aim: Migraine is a risk factor for the formation of silent brain white matter lesions (WMLs) that are possibly ischemic in nature. Although dysfunction of the Larginine/nitric oxide (NO) pathway has been associated with oxidative stress and endothelial dysfunction in migraine, its role in WML development was not specifically investigated. Thus, this prospective study aimed to measure the serum concentrations of the NO substrate L-arginine, the NO synthase inhibitor asymmetric dimethylarginine (ADMA), and the Larginine transport regulator symmetric dimethylarginine (SDMA) in migraine patients in a headache-free period.

Methods: All subjects underwent MR imaging to assess for the presence of WMLs on fluidattenuated inversion recovery imaging. Altogether 109 migraine patients (43 with lesions, 66 without lesions) and 46 control subjects were studied. High-performance liquid chromatography was utilized to quantify L-arginine, ADMA and SDMA serum
\end{abstract}


concentrations. Migraine characteristics were investigated, and participants were screened for risk factors that can lead to elevated serum ADMA levels independent of migraine.

Results: Migraine patients and controls did not differ in regard to vascular risk factors. Migraineurs with WMLs had a longer disease duration $(\mathrm{P}<.001)$ and a higher number of lifetime headache attacks $(\mathrm{P}=.005)$ than lesion-free patients. Higher L-arginine serum levels were found in both migraine subgroups compared to controls $(\mathrm{P}<.001)$. Migraine patients with WMLs showed higher ADMA concentrations than lesion-free patients and controls $(\mathrm{P}<$ .001 , for both). In migraineurs, the presence of WML, aura and increasing age proved to be significant predictors of increased ADMA levels $(\mathrm{P}=.008, .047$ and .012 , respectively). SDMA serum levels of lesional migraineurs were higher than in nonlesional patients $(\mathrm{P}<$ $.001)$. The presence of lesion and increasing age indicated an increased SDMA level $(\mathrm{P}=.017$ and .001 , respectively. Binary logistic regression analysis showed that ADMA level $(\mathrm{P}=$ $.006)$, increasing age $(\mathrm{P}=.017)$, and the total number of lifetime migraine attacks $(\mathrm{P}=.026)$ were associated with an increased likelihood of exhibiting WML. There was no significant effect of age on ADMA and SDMA concentrations in controls.

Conclusions: Elevated ADMA levels may impact the pathogenesis of migraine-related WMLs by influencing cerebrovascular autoregulation and vasomotor reactivity. Higher SDMA concentrations may indirectly influence NO synthesis by reducing substrate availability. Elevated L-arginine serum levels might reflect an increased demand for NO synthesis.

Keywords: migraine, white matter lesion, ADMA, SDMA, L-arginine, oxidative stress, vascular endothelial dysfunction 


\section{INTRODUCTION}

Migraine is a primary headache disorder with recurrent headache attacks (1). Migraine is an independent risk factor for the development of silent brain white matter lesions (WMLs) and infarcts (2-8). As such, WMLs are more prevalent in migraine patients than in the general population $(2,3)$, and they can develop at any age during the active migraine years $(3,9)$. Migraine, especially with aura, carries an increased risk for cerebro- and cardiovascular diseases that cannot be explained by traditional vascular risk factors (10-12). Although histopathological data are lacking in migraine, the microvascular ischemic injury theory $(5,13)$ was supported by our previous quantitative magnetic resonance imaging (MRI) data demonstrating intralesional tissue damage (14) consistent with previous studies of WMLs of ischemic origin $(15,16)$. In addition, longitudinal assessment of the same migraine patient group showed intralesional and intracerebral progression of WMLs over time (17).

A vascular etiology, such as impairment of the L-arginine/nitric oxide (NO) pathway with vascular endothelial dysfunction could explain the development and progression of WMLs, and could also provide a link between migraine and ischemic stroke or coronary heart disease. Endothelial NO-synthase (eNOS) utilizes L-arginine to generate the strong vasodilator, anti-atherogenic NO (18). Methylated analogs of L-arginine, symmetric and asymmetric dimethylarginine (SDMA and ADMA) are modulators of the L-arginine/NO pathway $(19,20)$. Both ADMA and SDMA levels are associated with an increased cardiovascular risk and mortality $(19,21)$. ADMA has also been found to be a marker of oxidative stress and endothelial dysfunction in migraine $(21,22)$.

Despite the growing evidence of oxidative stress and vascular endothelial activation in migraine (23-27), the abovementioned biomarkers of endothelial dysfunction have not been comprehensively analyzed in relation to WMLs. Therefore, our objective in the present study was to quantify the L-arginine, ADMA and SDMA serum concentrations of migraine patients 
with or without cerebral WMLs in a headache-free period, to detect group differences between lesional and non-lesional migraineurs, to investigate the effect of migraine characteristics, and to determine the differences between migraine patients and controls.

\section{PATIENTS AND METHODS}

\section{Subjects}

Between 2010 and 2013, a total of 177 patients fulfilling the International Headache Society (IHS) classification criteria for migraine with or without aura (1) were screened from the Outpatient Headache Clinic of the Department of Neurology, University of Pécs. A total of 109 migraineurs (93 females, mean age 36.7 \pm 10.8 years, age range 19-65 years; Table 1), 82 without and 27 with aura subtype remained and were prospectively enrolled in the study after exclusion of those with: (i) concurrent non-migraine headache types, (ii) focal neurological signs, (iii) abnormal screening blood test findings (e.g., abnormal lipid profile, etc.), (iv) suffering from any chronic disease other than medically treated hyperlipidemia or hyperuricemia, (v) active smoking habit. Patient selection was not restricted by age, since WMLs can be formed at any age during the active migraine headache years $(9,10)$. Since the migraineurs were either newly-diagnosed, or established patients with low headache frequency $(\leq 2 /$ month) maintaining adequate control on acute migraine regimens, none of them were on chronic prophylactic therapy during the study period. For acute migraine treatment, eletriptan, sumatriptan, ibuprofen, diclofenac and acetaminophen were utilized. As controls, 56 subjects were screened, and 46 age-matched healthy subjects ( 33 females, mean age $37.5 \pm 10.5$ years, age range $20-65$ years) were enrolled. These subjects were previously recruited via bulletin board advertisements throughout the University of Pécs accessible to students and staff. They had no history of any type of headache and passed the abovementioned exclusion criteria. All participants underwent detailed clinical investigations to uncover vascular risk factors, which themselves may cause elevation of serum 
dimethylarginine levels and WMLs. All subjects with previously diagnosed hypercholesterolemia were treated with statins, and those with elevated uric acid levels were on allopurinol at the time of blood sampling. The clinical data of patients and controls are presented in Table 1, while migraine characteristics are seen in Table 2.

All included participants underwent brain MRI in a headache free period utilizing the same scanner and acquisition protocol to evaluate the presence of white matter hyperintensities. Given the previous findings of focal tissue damage $(14,17)$, we will refer to these as WMLs later in the text. WMLs were detected in 43 migraineurs, whereas no WMLs or other structural abnormalities were found in the rest of the studied population including controls.

Migraine patients were divided into two subgroups based on presence of WMLs (L+) or absence of those (L-). Presence of aura, disease duration in years and monthly attack frequency were investigated, followed by the estimation of lifetime migraine attack number (average monthly attack number x 12 x number of migraine disease years to date) in all migraineurs.

Serum levels of L-arginine, ADMA and SDMA were quantified from fasting blood samples taken between 8 and 9 a.m. by venipuncture from the antecubital vein in all enrolled participants. Patients were headache free for at least 3 days before blood sampling. The MR scanning and the taking of blood samples were performed on the same week.

\section{MR scanning protocol and identification of white matter lesions}

A 3.0-Tesla clinical MRI scanner (Magnetom TIM Trio, Siemens Medical Solutions, Erlangen, Germany) with a 12-channel phased-array head coil was used for MR image acquisitions. Routine T1-, T2-weighted and fluid-attenuated inversion recovery (FLAIR) imaging were performed. For standard and accurate axial slice positioning the anterior and posterior commissural line (AC-PC line) was used as a reference for T2-weighted and FLAIR 
images. Sagittal T1-weighted images were obtained using a fast low angle shot (FLASH) 2dimensional (2D) sequence: $\mathrm{TR} / \mathrm{TE}=300 / 2.46 \mathrm{~ms}$; flip angle $=88^{\circ} ; 27$ slices; slice thickness $=4 \mathrm{~mm}$; distance factor $=30 \%$; Field of View $($ FOV $)=220 \times 220 \mathrm{~mm}^{2} ;$ matrix size $=$ 256x320; receiver bandwidth $=330 \mathrm{~Hz} /$ pixel. For T2-weighted images a turbo spin echo sequence was used: $\mathrm{TR} / \mathrm{TE}=6000 / 93 \mathrm{~ms}, 30$ slices, slice thickness $=4 \mathrm{~mm}$, distance factor $=$ $20 \%, \mathrm{FOV}=193 \times 220 \mathrm{~mm}^{2}$, matrix size $=280 \times 320$, bandwidth $=220 \mathrm{~Hz} /$ pixel, number of echo trains $=18$. A turbo spin echo sequence was also used for the FLAIR images: TR/TI/TE $=15710 / 2750 / 105 \mathrm{~ms}, 100$ slices, slice thickness $=1.5 \mathrm{~mm}$, distance factor $=0 \%$ (no gap), interleaved slice readout with two concatenation, FOV $=220 \times 220 \mathrm{~mm}^{2}$, matrix size $=$ $192 \times 192$, bandwidth $=400 \mathrm{~Hz} /$ pixel, number of echo trains $=14$.

Two qualified neuroradiologists who were blinded to migraine diagnosis and clinical data rated the white matter lesions. WMLs were considered if visible as hyperintense areas on T2-weighted and FLAIR images without hypointensity on T1-weighted scans and larger than $3 \mathrm{~mm}$ appearing in at least two consecutive slices (2) (Figure 1).

\section{Measuring serum concentrations of dimethylarginines and L-arginine}

The amino acids were extracted from the blood serum via solid phase extraction (SPE) according to the method of Nonaka et al. (28): a mixture of $250 \mu \mathrm{L}$ serum sample and $700 \mu \mathrm{L}$ borate buffer $(\mathrm{pH}=9.00)$ was mixed with the internal standard that was L-homoarginine hydrochloride (Aldrich, Germany) and $50 \mu \mathrm{L}$ of $1000 \mu \mathrm{mol} / \mathrm{L}$ solution was applied. Then the mixture with the internal standard was passed through SPE cartridges (OASIS ${ }^{\circledR}$ MCX $3 \mathrm{cc}$ SPE) at 750 mbar in a 12-column manifold (J. T. Baker). The elution was performed by concentrated aqueous ammonia (Reanal, Hungary), water and methanol with a volume ratio of 10/40/50. The solvent was evaporated beginning under a nitrogen atmosphere and finished in a vacuum at $60{ }^{\circ} \mathrm{C}$. The dry residue was dissolved in $200 \mu \mathrm{L}$ deionized water (Millipore, Milli-Q) and derivatized according to Molnar-Perl et al. (29); at room temperature the 
reaction time was 10 minutes. The high-performance liquid chromatography (HPLC) analysis was performed with a Waters 2695 Separations Module equipped with a thermostable autosampler $\left(5^{\circ} \mathrm{C}\right)$ and column module $\left(35^{\circ} \mathrm{C}\right)$. Separation was achieved with a Waters Symmetry SB C18 (4.6 x $150 \mathrm{~mm}, 3.5 \mu \mathrm{m})$ column and detected by a Waters 2475 fluorescence detector (Waters Milford, MA, USA) (30). For the measurements, $10 \mu \mathrm{L}$ was injected from the samples and the gradient elution was applied during the analysis with two mobile phases: A $\left(20 \mathrm{mM}\left(\mathrm{NH}_{4}\right)_{2} \mathrm{CO}_{3}\right.$ in water, $\left.\mathrm{pH}=7.50 \pm 0.05\right)$ and $\mathbf{B}$ (acetonitrile). The gradient program was as follows: 0-16 $\mathrm{min}: 91 \% \mathbf{A}$ and $9 \% \mathbf{B}, 16-17 \mathrm{~min}$ : linear change to 70 $\% \mathbf{A}$ and $30 \% \mathbf{B}$ and hold this for 5 minutes, 22-23 min: linear change to $91 \% \mathbf{A}, 9 \% \mathbf{B}$ and hold this for 12 minutes. The flow rate was constant $(1 \mathrm{~mL} / \mathrm{min})$. Arginine and homoarginine were detected at $\lambda_{\mathrm{ex}}=337 \mathrm{~nm}, \lambda_{\mathrm{em}}=520 \mathrm{~nm}$, but $\lambda_{\mathrm{em}}=454 \mathrm{~nm}$ was used for ADMA and SDMA.

\section{Statistical analysis}

Statistical analyses were performed utilizing the IBM SPSS Software (version 21, SPSS Inc, Chicago, IL). First, the distribution of each studied variable was assessed using the Kolmogorov-Smirnov and Shapiro-Wilk tests. Differences in age between the whole migraine group and healthy controls were assessed by the Mann-Whitney U-test.

Univariate analyses. Differences of continuous variables (e.g., age, BMI, disease duration, migraine attack frequency, total number of migraine attacks, Larginine/ADMA/SDMA levels) among groups (L+, L-, control) were compared using the Kruskal-Wallis test followed by the Mann-Whitney U test. Differences in binary population characteristics (e.g., gender, smoking, hypercholesterolemia, hyperuricemia, elevated CRP level) among the same groups were assessed utilizing Pearson's chi-square test.

Multivariate analyses. First, we tested predictors of L-arginine/ADMA/SDMA levels using stepwise multiple linear regression analyses. Age, gender, disease duration, migraine 
attack frequency, total number of migraine attacks and presence of aura were included as independent variables along with the grouping variable ( + + vs. L-), and Larginine/ADMA/SDMA level as the dependent variable. Similar analyses were performed to assess the L-arginine/ADMA/SDMA level differences between patient and control groups (L+ vs. control and L- vs. control), excluding migraine characteristics (not present in the control group) from the list of independent variables. In the control group, multiple linear regression analyses were performed to assess the potential effects of age and gender on Larginine, ADMA, and SDMA concentrations. Serum concentrations served as dependent, while age and gender as independent variables. The assumptions of multiple linear regression were satisfied, as judged by testing for linearity, and normality. In addition, in the patient group, binary logistic regression was performed including the covariates of age, gender, Larginine/ADMA/SDMA levels, disease duration, frequency of migraine attacks, total number of migraine attacks and presence of aura to assess the likelihood of WML presence. The final covariates were selected using a stepwise method (forward conditional).

Finally, Spearman's correlations were performed to assess the internal dependencies between the three reported lab-variables (L-arginine, ADMA, SDMA) in all subjects, and to investigate the correlation between age and disease duration in the migraine group. The level of statistical significance was set as $<.05$.

\section{RESULTS}

\section{Age}

Since the age of controls was matched to the whole migraine group, there was no significant difference in age between them. The Kruskal-Wallis test revealed significant age differences among migraine subgroups and controls $(\mathrm{P}<.001)$ (Table 1). Post-hoc testing indicated significant differences between all possible pairs of the three groups $(P<.05)$. 


\title{
Control group
}

Since the study subgroups were not age-, and gender-matched, the healthy control group was investigated next by multiple linear regression. There were no significant effects of either age or gender on L-arginine, ADMA, or SDMA concentrations; there were no interactions between age and gender (i.e. age*gender).

\section{Categorical data}

Regarding the gender of the subjects, and the presence of vascular risk factors, no significant differences were found among the groups (Table 1).

\section{Migraine characteristics}

Compared to lesion-free migraineurs, patients with WMLs had a longer disease duration $(P<$ .001 ; Table 2), and a higher number of lifetime headache attacks $(P=.005$; Table 2). The attack frequency did not show a significant difference between the L+ and L-groups (Table 2).

\section{L-arginine levels}

Markedly higher blood serum concentrations were measured in the migraine groups (L+ $173.6 \pm 55.6, \mathrm{~L}-164.8 \pm 53.4)$ than in the control group $(107.7 \pm 22.53)(P<.001$, in all comparisons; Table 2, Figure 2). Statistically significant differences were not found between the migraine groups (Table 2, Figure 2). Since the multiple linear regression analyses revealed no additional significant predictors (e.g., age, gender), the pattern of significance remained unchanged.

\begin{abstract}
ADMA levels
$\mathrm{L}+$ migraine patients $(0.781 \pm 0.155)$ showed higher serum concentrations than L- patients $(0.650 \pm 0.159)$ and controls $(0.663 \pm 0.077)(P<.001$, in both comparisons $)$ (Table 2, Figure 2). Controlling for the relevant covariates using multiple linear regression analyses, there was no change in the pattern of significance. When comparing the $\mathrm{L}+$ group to the control group
\end{abstract}


no additional significant predictors (e.g., age, gender) were found. In the comparison of the L+ and L- groups, aura and age proved to be additional significant predictors; the presence of WML, aura and increasing age indicated an increased ADMA level $(P=.008, .047$ and .012 respectively). There were no interactions between the independent variables.

\section{SDMA levels}

SDMA levels of $L+$ migraineurs $(0.559 \pm 0.094)$ were higher than $L-$ patients $(0.488 \pm 0.106)$ $(P<.001)$ and controls $(0.520 \pm 0.047)$, but the latter comparison was not statistically significant $(P=.07)$ (Table 2, Figure 2). SDMA levels of controls were higher than Lpatients $(P=.017)$. When comparing $\mathrm{L}+$ and $\mathrm{L}$ - groups using a multiple linear regression model, age proved to be an additional significant predictor; the presence of lesions and increasing age indicated an increased SDMA level $(P=.017$ and .001 , respectively). Comparing the L- and control groups, age proved to be a significant predictor (increasing age associated with increased SDMA level, $P=.011$ ), but the group difference (i.e., L- vs. control) was no longer significant $(P=.145)$. A significant interaction was found between the grouping variable and age $(P=.037)$.

\section{Binary logistic regression analysis}

The logistic regression model explained 37.4\% (Nagelkerke $R^{2}$ ) of the variance in WMLs and correctly classified $71.6 \%$ of WMLs. ADMA levels were the most significant independent predictors of WML presence, with more than an 85-fold higher likelihood of exhibiting WMLs in those with a $1 \mu \mathrm{mol} / \mathrm{L}$ elevation in $\mathrm{ADMA}(\operatorname{Exp}(\mathrm{B})=85.33, P=.006)$. Increasing age and total number of migraine attacks were also associated with an increased likelihood of exhibiting WML $(\operatorname{Exp}(\mathrm{B})=1.06, P=.017$ and $\operatorname{Exp}(\mathrm{B})=1.001, P=.026$, respectively $)$. There were no interactions between the independent predictors. None of the other examined variables added significantly to the model. 


\section{Spearman's correlations}

The ADMA level was positively correlated with both L-arginine and SDMA levels $(\rho=.158$, $P<.05$ and $\rho=.403, P<.001$, respectively). No significant correlation was found between the L-arginine and SDMA levels. A significant positive correlation was found between age and disease duration in the whole migraine group $(\rho=.628, P<.001)$ and in both subgroups $(\mathrm{L}+, \rho=.703, P<.001 ; \mathrm{L}-, \rho=.479, P<.001)$, as well.

\section{DISCUSSION}

The main finding of the present study is the elevated serum ADMA concentration in migraine patients with WMLs outside the attack period. ADMA levels were the best predictor of WMLs, independent of other significant factors such as age and estimated life-time headache attack number. Higher SDMA serum levels distinguished lesional migraine patients from lesion-free patients, while the elevated L-arginine concentrations differentiated migraineurs from controls.

\section{Age, vascular risk factors, migraine characteristics}

Increasing age was associated with an increased likelihood of exhibiting WMLs, and older age proved to be a predictor of higher ADMA and SDMA in migraineurs with lesions. Since positive correlation was found between age and disease duration, and there were no significant effects of age on ADMA and SDMA concentrations in controls, long duration of migraine, rather than older age, may explain the elevation of dimethylarginines.

Increased plasma ADMA concentrations have been associated with the presence of numerous vascular risk factors and chronic diseases such as obesity, hypertension, diabetes, dyslipidemia, hyperhomocysteinemia, ischemic heart disease, transient ischemic attack, silent brain infarcts, ischemic stroke, renal and liver failure, smoking and physical inactivity $(19,31)$. Vascular risk factors were rare in both patients and controls in our study, and all of them were treated during the study period. It is known that lipid-lowering therapy and 
smoking cessation reverse the endothelial dysfunction, if present (32). Therefore, a significant influence of vascular risk factors on the findings is unlikely.

In the present study, migraine patients with WMLs had a longer disease duration than nonlesional patients, and it was associated with a higher number of lifetime headache attacks. The number of lifetime headache attacks proved to be an independent predictor of WMLs, while the presence of aura indicated higher ADMA levels in migraineurs. Beyond the investigated migraine parameters, there are other factors such as attack intensity and duration, frequency and severity of the cortical spreading depression, which may have an influence on lesion formation. In concordance with previous studies $(22,27)$, the interictal elevation of ADMA in lesional patients indicate that oxidative stress can be present in both the ictal and interictal phases in migraine.

Effects of migraine on the biosynthesis and metabolism of dimethylarginines and Larginine

NO is produced by vascular endothelial cells, and plays a crucial role in the regulation of blood pressure, cerebral blood flow and neuroprotection $(18,33)$. The amino acid L-arginine is the main precursor of NO (Figure 3) (20,34). Posttranslational methylation of arginine residues on nuclear proteins leads to the generation of ADMA, SDMA and N-monomethyl-Larginine (L-NMMA) that are released into the cytosol upon proteolysis, then migrate into the extracellular space and thence into the blood plasma (35). Both ADMA and the less potent LNMMA are competitive inhibitors of all three isoforms of NOS, thus lowering the NO levels (35). The concentration of ADMA and L-NMMA is regulated mainly by degradation in the endothelial cells by the dimethylarginine dimethylaminohydrolase-2 isoform (DDAH-2), and in a smaller degree by urinary excretion $(35,36)$. SDMA is the structural counterpart of ADMA, and like ADMA, blocks cellular L-arginine uptake competitively, thus indirectly influencing NO bioavailability by reducing substrate availability (37-39). 
Since DDAH-2 is sensitive to oxidative stress triggered by the excessive generation of NO, under pathophysiological conditions, e.g., cardiovascular diseases and migraine, reactive O2 species (ROS) inhibit DDAH-2 activity with corresponding accumulation of ADMA (35). It is conceivable that the NO-caused vasodilatation is overbalanced by the increased amount of ADMA during migraine headache which may lead to a reduced bioavailability of NO, vasoconstriction with cerebral hypoperfusion and endothelial dysfunction (22). Since elevation of NO and ADMA concentrations are not restricted to the ictal state (22), inhibition of eNOS can also be present in a headache-free period. Chronic endothelial dysfunction has a role in mediating impaired cerebral autoregulation, and in the small perforating cerebral blood vessels it could result in poor white matter blood supply and the accumulation of white matter injury $(40,41)$.

It is probable that migraine is a systemic factor of vascular endothelial injury and WML development during the active headache years. Our findings support the importance of migraine headache management to avoid vascular complications of migraine. This includes not only acute and prophylactic headache treatments, but also the pharmacotherapy of comorbid cerebro- and cardiovascular diseases, as well as lifestyle changes.

\section{Comparability of serum and plasma L-arginine and dimethylarginine measurements}

The samples were measured with the internal standard method using L-homoarginine as the internal standard in the present study. L-homoarginine with its similar structure and chemical properties to ADMA, SDMA and L-arginine provides a chance to eliminate the matrix effects and the loss of the components during the sample preparation. Furthermore, the calibrants were prepared the same way as the samples. Thus, it can be assumed that there is no significant influence on the comparability of the results because the matrix effect can be eliminated. 


\section{Study limitations}

The lack of age- and sex-matched study subgroups may limit the comparability of groups. Although hyperhomocysteinemia is a cardiovascular risk factor, blood homocysteine levels were not measured in the present study.

\section{Conclusion}

The elevated ADMA levels in lesional migraineurs may indicate a role of migraine-related vascular endothelial dysfunction in the development of WMLs, supporting the ischemic injury theory of WML formation. These findings indicate that elevated ADMA concentrations may be a risk factor for clinically silent brain WMLs and point out the necessity of therapeutic interventions. SDMA may also have a role in lesion formation by indirect inhibition of NO bioavailability. The higher L-arginine serum concentrations might reflect an increased demand for NO synthesis in migraine.

\section{Clinical implications}

- Elevated ADMA concentrations may be a risk factor for clinically silent brain WMLs.

- Detection of ADMA levels in the clinic may help to estimate the risk of vascular endothelium impairment in migraineurs.

- The elevation of ADMA in migraine patients with lesions point to the importance of the clinical management of migraine headache and the pharmacotherapy of comorbid cerebral and cardiovascular diseases.

\section{Funding}

This work was supported by grants from EEA/Norwegian Financial Mechanism HU 0114 "Save what can be saved" - applied neurological research using high-field magnetic resonance imaging and by TÁMOP-4.2.1/B. N.K. was supported by the Bolyai Scholarship of the Hungarian Academy of Science. N.K. was supported by OTKA PD 103964. 


\section{Conflict of interest}

None declared.

\section{Ethics and institutional review board approval}

All subjects provided informed consent. Studies were performed in accordance with the approval (4022) of the Regional Research Ethics Committee of the Medical Center, Pécs.

\section{REFERENCES}

1. Headache Classification Committee of the International Headache Society (IHS). The International Classification of Headache Disorders, 3rd edition (beta version). Cephalalgia. 2013;33:629-808.

2. Vermeer SE, Hollander M, van Dijk EJ, Hofman A, Koudstaal PJ, Breteler MMB. Silent brain infarcts and white matter lesions increase stroke risk in general population. Stroke. 2003;34:1126-1129.

3. Swartz RH, Kern RZ. Migraine is associated with magnetic resonance imaging white matter abnormalities: a meta-analysis. Arch Neurol. 2004;61:1366-1368.

4. Kruit MC, van Buchem MA, Hofman PA, Bakkers JT, Terwindt GM, Ferrari MD, Launer LJ. Migraine is a risk factor for subclinical brain lesions. JAMA. 2004;291:427434.

5. Kruit MC, Launer LJ, Ferrari MD, van Buchem MA. Brain stem and cerebellar hyperintense lesions in migraine. Stroke. 2006;37:1109-1112.

6. Kruit MC, van Buchem MA, Launer LJ, Terwindt GM, Ferrari MD. Migraine is associated with an increased risk of deep white matter lesions, subclinical posterior circulation infarcts and brain iron accumulations: The population-based MRI CAMERA study. Cephalalgia. 2010;30:129-136. 
7. Palm-Meinders IH, Koppen H, Terwindt GM, Launer LJ, Konishi J, Moonen JM, Bakkers JT, Hofman PA, van Lew B, Middelkoop HA, van Buchem MA, Ferrari MD, Kruit MC. Structural brain changes in migraine. JAMA. 2012;308:1889-1897.

8. Monteith T, Gardener H, Rundek T, Dong C, Yoshita M, Elkind MS, DeCarli C, Sacco RL, Wright CB. Migraine, white matter hyperintensities, and subclinical brain infarction in a diverse community: the northern Manhattan study. Stroke. $2014 ; 45: 1830-1832$.

9. Eidlitz-Markus T, Zeharia A, Haimi-Cohen Y, Konen O. MRI white matter lesions in pediatric migraine. Cephalalgia. 2013;33:906-913.

10. Kurth T, Gaziano JM, Cook NR, Logroscino G, Diener HC, Buring JE. Migraine and risk of cardiovascular disease in women. JAMA. 2006 Jul 19;296:283-291.

11. Lee ST, Chu K, Jung KH, Kim DH, Kim EH, Choe VN, Kim JH, Im WS, Kang L, Park JE, Park HJ, Park HK, Song EC, Lee SK, Kim M, Roh JK. Decreased number and function of endothelial progenitor cells in patients with migraine. Neurology. 2008;70:1510-1517.

12. Sacco S, Cerone D, Carolei A. Comorbid neuropathologies in migraine: an update on cerebrovascular and cardiovascular aspects. J Headache Pain. 2008;9:237-248.

13. Bednarczyk EM, Remler B, Weikart C, Nelson AD, Reed RC. Global cerebral blood flow, blood volume, and oxygen metabolism in patients with migraine headache. Neurology. 1998;50:1736-1740.

14. Aradi M, Schwarcz A, Perlaki G, Orsi G, Kovács N, Trauninger A, Kamson DO, Erdélyi-Bótor S, Nagy F, Nagy SA, Dóczi T, Komoly S, Pfund Z. Quantitative MRI studies of chronic brain white matter hyperintensities in migraine patients. Headache. 2013;53:752-763. 
15. Oppenheimer SM, Bryan RN, Conturo TE, Soher BJ, Preziosi TJ, Barker PB. Proton magnetic resonance spectroscopy and gadolinium-DTPA perfusion imaging of asymptomatic MRI white matter lesions. Magn Reson Med. 1995;33:61-68.

16. Walker PM, Ben Salem D, Lalande A, Giroud M, Brunotte F. Time course of NAA T2 and $\mathrm{ADC}(\mathrm{w})$ in ischaemic stroke patients: $1 \mathrm{H}$ MRS imaging and diffusion-weighted MRI. J Neurol Sci. 2004;220:23-28.

17. Erdélyi-Bótor S, Aradi M, Kamson DO, Kovács N, Perlaki G, Orsi G, Nagy SA, Schwarcz A, Dóczi T, Komoly S, Deli G, Trauninger A, Pfund Z. Changes of migraine-related white matter hyperintensities after three years: a longitudinal MRI study. Headache. 2015;55:55-70.

18. Toda N, Ayajiki K, Okamura T. Cerebral blood flow regulation by nitric oxide in neurological disorders. Can J Physiol Pharmacol. 2009;87:581-594.

19. Böger RH, Sullivan LM, Schwedhelm E, Wang TJ, Maas R, Benjamin EJ, Schulze F, Xanthakis V, Benndorf RA, Vasan RS. Plasma asymmetric dimethylarginine and incidence of cardiovascular disease and death in the community. Circulation. 2009; 119:1592-600.

20. Schwedhelm E, Wallaschofski H, Atzler D, Dörr M, Nauck M, Völker U, Kroemer HK, Völzke H, Böger RH, Friedrich N. Incidence of all-cause and cardiovascular mortality predicted by symmetric dimethylarginine in the population-based study of health in pomerania. PLoS One. 2014;9(5):e96875.

21. Silva FA, Rueda-Clausen CF, Silva SY, Zarruk JG, Guzmán JC, Morillo CA, Vesga B, Pradilla G, Flórez M, López-Jaramillo P. Endothelial function in patients with migraine during the interictal period. Headache. 2007;47:45-51. 
22. Uzar E, Evliyaoglu O, Toprak G, Acar A, Yucel Y, Calisir T, Cevik MU, Tasdemir N. Increased asymmetric dimethylarginine and nitric oxide levels in patients with migraine. J Headache Pain. 2011;12:239-243.

23. Ciancarelli I, Tozzi-Ciancarelli MG, Di Massimo C, Marini C, Carolei A. Urinary nitric oxide metabolites and lipid peroxidation by-products in migraine. Cephalalgia. $2003 ; 23: 39-42$.

24. Yilmaz G, Sürer H, Inan LE, Coskun O, Yücel D. Increased nitrosative and oxidative stress in platelets of migraine patients. Tohoku J Exp Med. 2007;211:23-30.

25. Tietjen GE, Herial NA, White L, Utley C, Kosmyna JM, Khuder SA. Migraine and biomarkers of endothelial activation in young women. Stroke. 2009;40:2977-2982.

26. Gruber HJ, Bernecker C, Lechner A, Weiss S, Wallner-Blazek M, Meinitzer A, Höbarth G, Renner W, Fauler G, Horejsi R, Fazekas F, Truschnig-Wilders M. Increased nitric oxide stress is associated with migraine. Cephalalgia. 2010;30:486492.

27. Bernecker C, Ragginer C, Fauler G, Horejsi R, Möller R, Zelzer S, Lechner A, Wallner-Blazek M, Weiss S, Fazekas F, Bahadori B, Truschnig-Wilders M, Gruber HJ. Oxidative stress is associated with migraine and migraine-related metabolic risk in females. Eur J Neurol. 2011;18:1233-1239.

28. Nonaka S, Tsunoda M, Imai K, Funatsu T. High-performance liquid chromatographic assay of NG-monomethyl-L-arginine, NG,NG-dimethyl-L-arginine, NG,NG'dimethyl-L-arginine using 4-fluoro-7-nitro-2,1,3-benzoxadiazole as a fluorescent reagent. J Chromatograph A. 2005;1066:41-45.

29. Molnar-Perl I, Vasanits A. Stability and charactheristics of the o-phthaldialdehyd/3mercaptoprpionic acid and o-phthaldialdehyd/N-acetyl-L-cysteine reagents and their 
amino acid derivatives measured by high-performance liquid chromatography. $J$ Chromatograph A. 1999;835:73-91.

30. Zsuga J, Török J, Magyar MT, Valikovics A, Gesztelyi R, Lenkei A, Csiba L, Kéki S, Zsuga M, Bereczki D. Dimethylarginines at the crossroad of insulin resistance and atherosclerosis. Metabolism. 2007;56:394-399.

31. Pikula A, Böger RH, Beiser AS, Maas R, DeCarli C, Schwedhelm E, Himali JJ, Schulze F, Au R, Kelly-Hayes M, Kase CS, Vasan RS, Wolf PA, Seshadri S. Association of plasma ADMA levels with MRI markers of vascular brain injury: Framingham offspring study. Stroke. 2009;40:2959-2964.

32. Widlansky ME, Gokce N, Keaney JF Jr, Vita JA. The clinical implications of endothelial dysfunction. J Am Coll Cardiol. 2003;42:1149-1160.

33. Herrera M, Garvin JL. Novel role of AQP-1 in NO-dependent vasorelaxation. Am J Physiol Renal Physiol. 2007;292:F1443-1451.

34. Vallance P, Leone A, Calver A, Collier J, Moncada S. Accumulation of an endogenous inhibitor of nitric oxide synthesis in chronic renal failure. Lancet. 1992;339:572-575.

35. Ghebremariam YT, Erlanson DA, Yamada K, Cooke JP. Development of a dimethylarginine dimethylaminohydrolase (DDAH) assay for high-throughput chemical screening. J Biomol Screen. 2012;17:651-661.

36. Leiper JM, Santa Maria J, Chubb A, MacAllister RJ, Charles IG, Whitley GS, Vallance P. Identification of two human dimethylarginine dimethylaminohydrolases with distinct tissue distributions and homology with microbial arginine deiminases. Biochem J. 1999;343:209-214. 
37. Closs EI, Basha FZ, Habermeier A, Förstermann U. Interference of L-arginine analogues with L-arginine transport mediated by the $\mathrm{y}+$ carrier hCAT-2B. Nitric Oxide. $1997 ; 1: 65-73$.

38. Strobel J, Mieth M, Endress B, Auge D, König J, Fromm MF, Maas R. Interaction of the cardiovascular risk marker asymmetric dimethylarginine (ADMA) with the human cationic amino acid transporter 1 (CAT1). J Mol Cell Cardiol. 2012;53:392-400.

39. Betz B, Möller-Ehrlich K, Kress T, Kniepert J, Schwedhelm E, Böger RH, Wanner C, Sauvant C, Schneider R. Increased symmetrical dimethylarginine in ischemic acute kidney injury as a causative factor of renal L-arginine deficiency. Transl Res. $2013 ; 162: 67-76$.

40. Lin JX, Tomimoto H, Akiguchi I, Matsuo A, Wakita H, Shibasaki H, Budka H. Vascular cell components of the medullary arteries in Binswanger's disease brains: a morphometric and immunoelectron microscopic study. Stroke. 2000;31:1838-1842.

41. De Reuck J. The human periventricular arterial blood supply and the anatomy of cerebral infarctions. Eur Neurol. 1971;5:321-334. 
Table 1. Clinical data of migraine patients and healthy controls and differences among groups

\begin{tabular}{lcccc}
\hline $\begin{array}{l}\text { Investigated } \\
\text { parameters }\end{array}$ & $\begin{array}{c}\text { Migraine patients } \\
\text { with lesions } \\
(n=43)\end{array}$ & $\begin{array}{c}\text { Migraine patients } \\
\text { without lesions } \\
(n=66)\end{array}$ & $\begin{array}{c}\text { Controls } \\
(n=46)\end{array}$ & $\begin{array}{c}\text { Differences } \\
(P \text { - value })\end{array}$ \\
\hline Age (years) & $41.7(21-65)$ & $32.7(19-54)$ & $37.5(20-65)$ & $<.001^{\prime}$ \\
Female/male & $38 / 5$ & $55 / 11$ & $33 / 13$ & $.107^{\prime \prime}$ \\
Hypertension & $0 / 43$ & $0 / 66$ & $0 / 46$ & N/A \\
Diabetes & $0 / 43$ & $0 / 66$ & $0 / 46$ & N/A \\
Kidney disease & $0 / 43$ & $0 / 66$ & $0 / 46$ & N/A \\
Hepatopathy & $0 / 43$ & $0 / 66$ & $0 / 46$ & N/A \\
High LDLcholesterol* & $5 / 43$ & $6 / 66$ & $3 / 46$ & $.886^{\prime \prime}$ \\
Hyperuricemia** & $1 / 43$ & $2 / 66$ & $3 / 46$ & $.660^{\prime \prime}$ \\
Elevated CRP level*** & $\mathbf{2 / 4 3}$ & $\mathbf{5} / 66$ & $2 / 46$ & $.228^{\prime \prime}$ \\
Thyroid disorder & $0 / 43$ & $0 / 66$ & $0 / 46$ & N/A \\
$\begin{array}{l}\text { Systemic autoimmune } \\
\text { disease }\end{array}$ & $0 / 43$ & $0 / 66$ & $0 / 46$ & N/A \\
Smoking**** & $6 / 43$ & $8 / 66$ & $5 / 46$ & $.445^{\prime \prime}$ \\
$\begin{array}{l}\text { Cardiac source } \\
\text { of embolism }\end{array}$ & $0 / 43$ & $0 / 66$ & $0 / 46$ & N/A \\
BMI (kg/m2) & $23.69 \pm 2.21$ & $23.29 \pm 2.46$ & $23.65 \pm 2.12$ & $.267^{\prime}$
\end{tabular}

LDL: low-density lipoprotein; CRP: C-reactive protein; BMI: body mass index; N/A: Not Applicable; Participants were treated with statins* (LDL $<3.4 \mathrm{mmol} / \mathrm{l}$ ) and allopurinol** (uric acid $<350 \mathrm{mmol} / \mathrm{l}$ ) at the time of blood sample taking; ***CRP was between

5.0 and $7.0 \mathrm{mg} / \mathrm{l}$ in elevated cases; ****History of smoking, no active smoking; 'Kruskal-Wallis test; "Pearson's chi-square test 
Table 2. Results of measured variables and statistical differences between migraine subgroups and controls

\begin{tabular}{|c|c|c|c|c|c|c|c|c|c|c|}
\hline & \multicolumn{6}{|c|}{ White matter lesions } & \multicolumn{4}{|c|}{ Statistics } \\
\hline & \multicolumn{2}{|c|}{ Lesion $+(n=43)^{*}$} & \multicolumn{2}{|c|}{ Lesion- $(n=66)^{* *}$} & \multicolumn{2}{|c|}{ Control $(n=46)$} & \multicolumn{3}{|c|}{ Mann-Whitney test } & \multirow{2}{*}{ Kruskal-Wallis test } \\
\hline & Mean & SD & Mean & SD & Mean & SD & L+ vs. L- & $\mathrm{L}+$ vs. $\mathrm{C}$ & L- vs. C & \\
\hline $\begin{array}{c}\text { Disease duration } \\
\text { (years) }\end{array}$ & 20.12 & 11.84 & 11.98 & 7.45 & - & - & $<.001$ & - & - & $<.001$ \\
\hline $\begin{array}{l}\text { Migraine attack } \\
\text { frequency/month }\end{array}$ & 3.88 & 3.24 & 3.43 & 3.04 & - & - & .45 & - & - & .45 \\
\hline $\begin{array}{l}\text { Total number of } \\
\text { migraine attacks }\end{array}$ & 900.3 & 913.4 & 428.4 & 398.5 & - & - & .005 & - & - & .005 \\
\hline L-arginine & 173.6 & 55.6 & 164.8 & 53.4 & 107.7 & 22.53 & .55 & $<.001$ & $<.001$ & $<.001$ \\
\hline ADMA & 0.781 & 0.155 & 0.650 & 0.159 & 0.663 & 0.077 & $<.001$ & $<.001$ & 0.48 & $<.001$ \\
\hline SDMA & 0.559 & 0.094 & 0.488 & 0.106 & 0.520 & 0.047 & $<.001$ & 0.07 & 0.017 & $<.001$ \\
\hline
\end{tabular}

ADMA $=$ asymmetric dimethylarginine; SDMA $=$ symmetric dimethylarginine; ${ }^{*} 13$ migraine patients with aura; $* * 14$ migraine patients with aura 


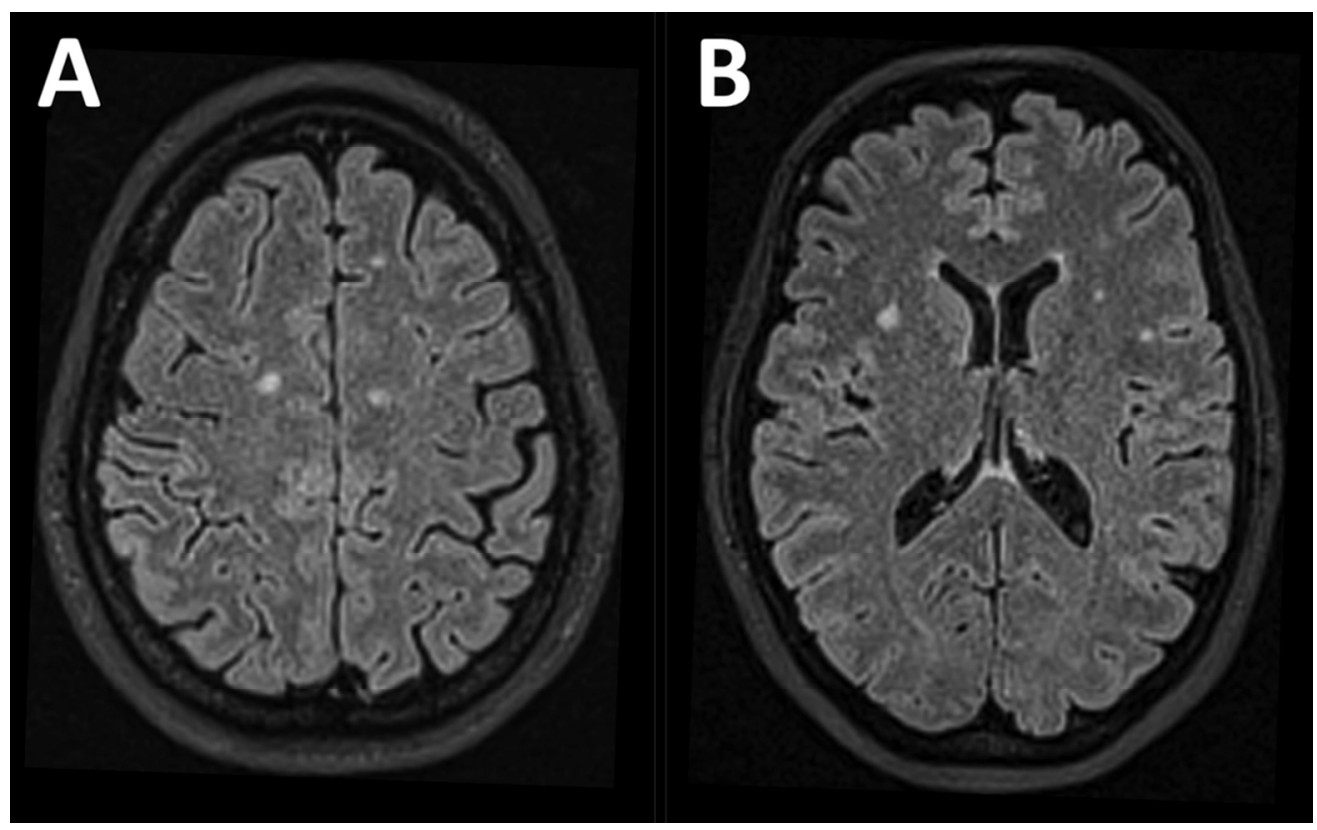

Figure 1. Axial fluid-attenuated inversion recovery brain MRI images of a migraine patient with aura. The figure shows bifrontal white matter hyperintensities in two different slices ( $A$ and $B$ ). $93 \times 58 \mathrm{~mm}(300 \times 300$ DPI) 

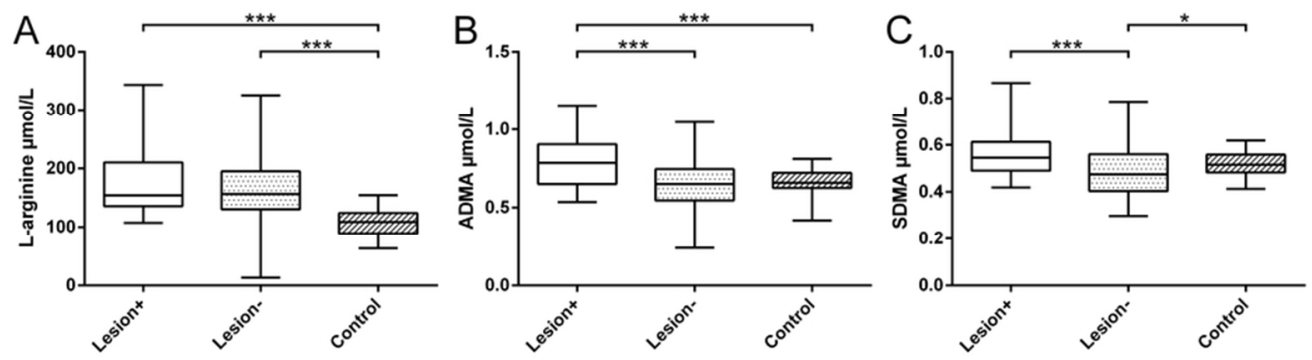

Figure 2. L-arginine, asymmetric and symmetric dimethylarginine (ADMA and SDMA) serum concentrations in migraineurs and controls. The figure demonstrates the differences between the lesion+, and the lesionmigraine groups and the control group. Whiskers are set at minimum and maximum, the horizontal line marks the median, whereas the box indicates the interquartile range $(25-75 \%)$. The statistically significant differences between the groups are indicated by $*$ on the figures ( $* \mathrm{P}<.05, * * * \mathrm{p}<.001)$. $78 \times 22 \mathrm{~mm}(300 \times 300 \mathrm{DPI})$ 
Figure 3. Effects of migraine headache on the biosynthesis and metabolism of dimethylarginines and Larginine. SAM = S-adenosyl-methionine, SAH = S-adenosyl-homocysteine, $\mathrm{PRMTs}=$ protein arginine methyltransferases, ADMA $=$ asymmetric dimethylarginine, L-NMMA $=\mathrm{N}$-monomethyl-L-arginine, SDMA $=$ symmetric dimethylarginine, $\mathrm{NO}=$ nitric oxide, DDAH-2 = dimethylarginine dimethylaminohydrolase-2, eNOS $=$ endothelial nitric oxide synthase. 
STROBE Statement — checklist of items that should be included in reports of observational studies

\begin{tabular}{|c|c|c|c|c|}
\hline & $\begin{array}{l}\text { Item } \\
\text { No. }\end{array}$ & Recommendation & $\begin{array}{l}\text { Page } \\
\text { No. }\end{array}$ & $\begin{array}{c}\text { Relevant text from } \\
\text { manuscript }\end{array}$ \\
\hline \multirow[t]{2}{*}{ Title and abstract } & \multirow[t]{2}{*}{1} & (a) Indicate the study's design with a commonly used term in the title or the abstract & 1 & prospective \\
\hline & & $\begin{array}{l}\text { (b) Provide in the abstract an informative and balanced summary of what was done and what was } \\
\text { found }\end{array}$ & $1-2$ & \\
\hline \multicolumn{5}{|l|}{ Introduction } \\
\hline Background/rationale & 2 & Explain the scientific background and rationale for the investigation being reported & 3 & \\
\hline Objectives & 3 & State specific objectives, including any prespecified hypotheses & $3-4$ & \\
\hline \multicolumn{5}{|l|}{ Methods } \\
\hline Study design & 4 & Present key elements of study design early in the paper & $4-5$ & \\
\hline Setting & 5 & $\begin{array}{l}\text { Describe the setting, locations, and relevant dates, including periods of recruitment, exposure, } \\
\text { follow-up, and data collection }\end{array}$ & $4-8$ & \\
\hline \multirow[t]{4}{*}{ Participants } & \multirow[t]{4}{*}{6} & $\begin{array}{l}\text { (a) Cohort study-Give the eligibility criteria, and the sources and methods of selection of } \\
\text { participants. Describe methods of follow-up }\end{array}$ & & \\
\hline & & $\begin{array}{l}\text { Case-control study - Give the eligibility criteria, and the sources and methods of case } \\
\text { ascertainment and control selection. Give the rationale for the choice of cases and controls } \\
\text { Cross-sectional study-Give the eligibility criteria, and the sources and methods of selection of } \\
\text { participants }\end{array}$ & $4-5$ & \\
\hline & & $\begin{array}{l}\text { (b) Cohort study-For matched studies, give matching criteria and number of exposed and } \\
\text { unexposed }\end{array}$ & & \\
\hline & & $\begin{array}{l}\text { Case-control study-For matched studies, give matching criteria and the number of controls per } \\
\text { case }\end{array}$ & $4-5$ & \\
\hline Variables & 7 & $\begin{array}{l}\text { Clearly define all outcomes, exposures, predictors, potential confounders, and effect modifiers. } \\
\text { Give diagnostic criteria, if applicable }\end{array}$ & $4-7$ & \\
\hline $\begin{array}{l}\text { Data sources/ } \\
\text { measurement }\end{array}$ & $8 *$ & $\begin{array}{l}\text { For each variable of interest, give sources of data and details of methods of assessment } \\
\text { (measurement). Describe comparability of assessment methods if there is more than one group }\end{array}$ & $4-7$ & \\
\hline Bias & 9 & Describe any efforts to address potential sources of bias & $4-8$ & \\
\hline Study size & 10 & Explain how the study size was arrived at & $4-5$ & \\
\hline
\end{tabular}

Continued on next page 


\begin{tabular}{lcll}
\hline $\begin{array}{l}\text { Quantitative } \\
\text { variables }\end{array}$ & 11 & $\begin{array}{l}\text { Explain how quantitative variables were handled in the analyses. If applicable, describe which } \\
\text { groupings were chosen and why }\end{array}$ & $4-7$ \\
\hline $\begin{array}{l}\text { Statistical } \\
\text { methods }\end{array}$ & 12 & (a) Describe all statistical methods, including those used to control for confounding & $7-8$ \\
\cline { 2 - 3 } & & (b) Describe any methods used to examine subgroups and interactions & $7-8$ \\
\cline { 2 - 3 } & & $\begin{array}{l}\text { No missing } \\
\text { data }\end{array}$ \\
\cline { 2 - 3 } & & & \\
\hline
\end{tabular}

(d) Cohort study - If applicable, explain how loss to follow-up was addressed

Case-control study —If applicable, explain how matching of cases and controls was addressed $\quad$ 4-5, 7-8

Cross-sectional study - If applicable, describe analytical methods taking account of sampling strategy

(e) Describe any sensitivity analyses

NA

\begin{tabular}{llllll}
\hline Results & & & \\
\hline Participants & $13 *$ & (a) Report numbers of individuals at each stage of study—eg numbers potentially eligible, examined & $4-5,8-9$
\end{tabular}

for eligibility, confirmed eligible, included in the study, completing follow-up, and analysed
(b) Give reasons for non-participation at each stage
(c) Consider use of a flow diagram
NA

\begin{tabular}{llll}
\hline Descriptive data & $14^{*} \quad$ (a) Give characteristics of study participants (eg demographic, clinical, social) and information on & $4-5,8-11$
\end{tabular} exposures and potential confounders

(b) Indicate number of participants with missing data for each variable of interest $\quad$ NA

(c) Cohort study-Summarise follow-up time (eg, average and total amount) NA

$\begin{array}{llll}\text { Outcome data } & 15^{*} \text { Cohort study-Report numbers of outcome events or summary measures over time } & \text { NA }\end{array}$

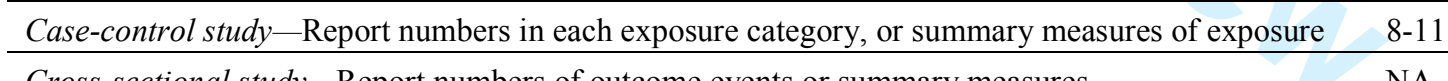

Cross-sectional study -Report numbers of outcome events or summary measures

Main results $\quad 16 \quad(a)$ Give unadjusted estimates and, if applicable, confounder-adjusted estimates and their precision

(eg, $95 \%$ confidence interval). Make clear which confounders were adjusted for and why they were included

(b) Report category boundaries when continuous variables were categorized

8-11

(c) If relevant, consider translating estimates of relative risk into absolute risk for a meaningful time

NA period

Continued on next page 


\begin{tabular}{lrlll}
\hline Other analyses & 17 & Report other analyses done-eg analyses of subgroups and interactions, and sensitivity analyses & $8-11$ \\
\hline Discussion & & & $11-14$ \\
\hline Key results & 18 & Summarise key results with reference to study objectives & $13-14$ \\
\hline Limitations & 19 & $\begin{array}{l}\text { Discuss limitations of the study, taking into account sources of potential bias or imprecision. Discuss } \\
\text { both direction and magnitude of any potential bias }\end{array}$ & 14 \\
\hline Interpretation & 20 & $\begin{array}{l}\text { Give a cautious overall interpretation of results considering objectives, limitations, multiplicity of } \\
\text { analyses, results from similar studies, and other relevant evidence }\end{array}$ & 14 \\
\hline Generalisability & 21 & Discuss the generalisability (external validity) of the study results & 14 \\
\hline Other information & & $\begin{array}{l}\text { Give the source of funding and the role of the funders for the present study and, if applicable, for the } \\
\text { Foriginal study on which the present article is based }\end{array}$ \\
\hline Funding & 22 &
\end{tabular}

*Give information separately for cases and controls in case-control studies and, if applicable, for exposed and unexposed groups in cohort and cross-sectional studies.

Note: An Explanation and Elaboration article discusses each checklist item and gives methodological background and published examples of transparent reporting. The STROBE checklist is best used in conjunction with this article (freely available on the Web sites of PLoS Medicine at http://www.plosmedicine.org/, Annals of Internal Medicine at http://www.annals.org/, and Epidemiology at http://www.epidem.com/). Information on the STROBE Initiative is available at www.strobe-statement.org. 